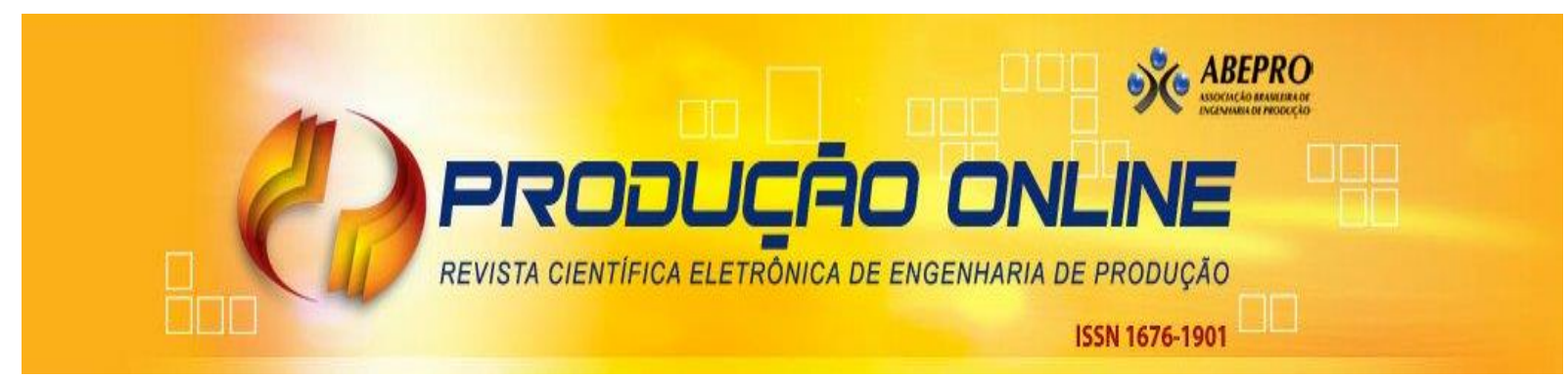

\title{
VIABILIDADE ECONÔMICA DE IMPLEMENTAÇÃO DA TECNOLOGIA RFID NA INDÚSTRIA DE SEMENTE DE SOJA
}

\section{ECONOMIC FEASIBILITY OF RFID TECHNOLOGY IMPLEMENTATION IN THE SOY SEED INDUSTRY}

\author{
Luiz Eduardo Bueno Borges* E-mail: luizeduardobueno@gmail.com \\ Alan Carlos Costa**E-mail: alan.costa@ifgoiano.edu.br \\ Paulo Cesar Bontempo* E-mail: paulo.bontempo@unialfa.com.br \\ Alcido Elenor Wander* alcido.wander@unialfa.com.br \\ ${ }^{*}$ Centro Universitário Alves Faria (UNIALFA), Goiânia, GO \\ **Instituto Federal Goiano (IF Goiano), Goiânia, GO
}

Resumo. O presente trabalho teve como objetivo avaliar a viabilidade econômica de implementação da tecnologia de RFID na logística interna de uma indústria de produção de semente de soja. Foi elaborado um estudo de caso em uma empresa de sementes de soja de Goiás. Também foi realizada uma prova de conceito e uma análise de viabilidade econômica, a partir de indicadores como o Valor Presente Líquido, Taxa Interna de Retorno e o Payback Descontado. A implementação de RFID em uma empresa de produção de sementes de soja se mostrou viável, tanto do ponto de vista técnico, como também econômico.

Palavras-chave: RFID. Indústria 4.0. Indústria de Sementes de Soja. Logística 4.0.

Abstract. The present study aimed to evaluate the economic feasibility of implementing the RFID technology in the internal logistics of a soybean seed production plant. A case study was carried out at a soybean seed company in Goiás state, Brazil. A proof of concept and an economic feasibility analysis were also carried out, based on indicators such as Net Present Value, Internal Rate of Return and Discounted Payback. The implementation of RFID in a soybean seed production company was technically and economically viable.

Key words: RFID. Industry 4.0. Soybean seed industry. Logistics 4.0.

\section{INTRODUÇÃO}

A evolução tecnológica nem sempre é um processo contínuo, podendo ser abrupto, uma vez que inovações disruptivas sejam introduzidas no mercado (CHRISTENSEN et al., 2017). À medida em que as inovações se tornam maduras, empresas tem acompanhado e implementado tecnologias oriundas das inovações a fim de obter vantagem competitiva, garantindo um crescimento contínuo e a longevidade do negócio independentemente do setor de atuação. 
Atualmente o setor do agronegócio exerce um importante papel na economia Brasileira, sendo que sua representatividade é de aproximadamente $1 / 4$ da composição total do PIB (CNA; CEPEA, 2017). Dada sua importância, é imprescindível a adoção e difusão de novas tecnologias pela cadeia agroindustrial, garantindo vantagem competitiva, otimização do processo produtivo e consequentemente um aumento na capacidade de gerar rentabilidade.

Nesse contexto, a cadeia produtiva da soja possui relevante papel no crescimento contínuo do agronegócio brasileiro. Para se ter uma ideia, a produção de soja na safra de 2016/2017 foi de 113,93 milhões de toneladas, em uma área plantada de aproximadamente 93 milhões de hectares, com produtividade média alcançada de 3,3 toneladas por hectare, rendimento $14,9 \%$ superior ao registrado na safra anterior, colocando o Brasil na segunda posição mundial em produção e no primeiro lugar em exportação (CONAB, 2017).

O presente trabalho tem como foco a indústria de produção de sementes, devido a sua importância tanto no âmbito econômico, quanto no tecnológico, haja vista que ela é responsável pela melhoria contínua da produtividade das lavouras, conectando os avanços da pesquisa de melhoramento vegetal e biotecnologia ao campo.

Atualmente acompanha-se o desenvolvimento da quarta revolução industrial, marcada pela digitalização da operação industrial, sendo denominada "Indústria 4.0" (KAGERMANN, 2013). Essa nova era industrial, centraliza a utilização de recursos e informações tecnológicas a fim de melhorar o processo de manufatura e negócio, que no atual cenário de alta competitividade, compeli a necessidade de tomada de decisão sob demanda e em tempo real.

Nesse novo contexto industrial, boa parte dos sistemas de controles, sensores e equipamentos estão conectados a redes, transportadores, seres humanos entre outros, o que exige uma logística que possibilite uma integração: tecnológica, rápida, conectada e inteligente. A tecnologia RFID ${ }^{1}$ possui grande potencial para assegurar o atendimento a essas exigências, tendo um grande potencial para inúmeras aplicações práticas na logística, gestão da cadeia de suprimentos, manufatura e sistemas de automação industrial.

\footnotetext{
${ }^{1}$ RFID - Radio-Frequency Identification consiste em uma tecnologia cuja principal função é a identificação por ondas de rádio, com alcances variáveis, de acordo com o chip utilizado nas etiquetas ou tags RFID (DUROC; KADDOUR, 2012).
} 
Diante do exposto, o presente artigo tem como finalidade avaliar a viabilidade econômica de implementação da tecnologia de RFID na logística interna de uma indústria de produção de semente de soja.

\section{TECNOLOGIA RFID E A LOGÍSTICA INTERNA DA INDUSTRIA DE SEMENTE DE SOJA}

Historicamente o Agronegócio possui considerável relevância na economia brasileira, de acordo com dados do Centro de Estudos Avançados em Economia Aplicada - CEPEA, sua representatividade é de aproximadamente $1 / 4$ da composição do PIB total, sendo que em 2016 sua participação foi de $23 \%$ com a estimativa de crescimento de $2 \%$ para 2017, enquanto o desempenho estimado para o PIB da economia é de expansão de 1,1\% (CNA; CEPEA, 2017).

A fatia do Agronegócio no PIB é representada por meio da soma de quatro segmentos: insumos para a agropecuária, produção, agropecuária básica ou primária, agroindústria (Processamento) e agrosserviços. A análise desses segmentos é feita para o ramo agrícola (Vegetal) e para o pecuário (Animal), ao serem somados, com as devidas ponderações, obtém-se a análise da cadeia do Agronegócio (CEPEA, 2017).

A cadeia produtiva da soja é caracterizada pela sequência objetiva de procedimentos técnicos de produção e distribuição, com atividades inter-relacionadas, configurando um ciclo produtivo (MOREIRA; ARRUDA; SILVA, 2015).

De acordo com Michels et al. (2003) a cadeia produtiva da soja pode ser segmentada em seis principais elos, sendo eles: Industria do Genoma, Indústria de

Produção de Sementes, Produção Rural, Distribuição, Industria de Beneficiamento/Armazenamento de Grãos e Indústria de Esmagamento de Grãos. Abaixo segue a descrição técnica de cada um desses elos.

- Indústria do Genoma - A cadeia produtiva da soja tem início a partir da indústria do genoma, que é responsável essencialmente pela genética e biotecnologia embarcada na semente que será multiplicada;

- Indústria de Produção de Sementes - Esse elo é responsável pela multiplicação da genética e do beneficiamento das sementes; 
- Produção Rural - Nesse elo é onde se instalam as unidades agrícolas produtivas, compostas principalmente pelas propriedades rurais cujos campos são destinados a cultura da soja;

- Distribuição - O setor de distribuição é responsável pelos registros de negócios que intermediam o campo e o mercado;

- Indústria de Beneficiamento/Armazenamento de Grãos - A soja enquanto matéria prima, pode ser exportada ainda como grão, sem ser industrializada, industrias que tem esse propósito compõem esse elo;

- Industria de Esmagamento de Grãos - As agroindústrias do setor foram denominadas de indústrias de esmagamento de grãos, e compõem esse elo, tendo como elos adjacentes, a indústria de alimentação, nutrição animal, atacadista de alimentos e varejista de alimentos.

No Brasil, as discussões e assuntos relacionados às cadeias do agronegócio iniciaram-se na década de 90, desde então o agronegócio pode ser analisado de maneira mais abrangente, contemplando uma análise mais detalhada, percorrendo as etapas que englobam desde a matéria prima até o produto final para o consumidor, tendo como base a metodologia norte americana (CSA) para análise dessas cadeias (MOREIRA; ARRUDA; SILVA, 2015).

Mesmo com características visuais e definição gramatical quase que idênticas, grão e semente se distinguem entre si, provocando uma falsa dicotomia.

Grão é um termo usado na agronomia que, de acordo com a ciência não é adequado para atribuir a frutos e sementes, sendo que na botânica, grão é o pólen da flor. Já a semente consiste no órgão que surge após a fertilização e desenvolvimento do óvulo, sendo resultado dessa fertilização (SALATINO, 2017).

A indústria de sementes possui um importante papel econômico na cadeia produtiva, sendo um dos principais responsáveis pela melhoria contínua da produtividade das lavouras, conectando os avanços da pesquisa de melhoramento vegetal e biotecnologia ao campo (HOLANDA, [S.d.]).

De acordo com Lima e Bueno (2001) a indústria de produção de sementes de soja pode ser caracterizada em três principais segmentos, sendo eles: Criação, melhoramento e adaptação de materiais genéticos; Multiplicação de sementes; Distribuição de sementes; 
Esses segmentos são apoiados pelo Serviço Nacional de Proteção de cultivares - SNPC, que tem a finalidade de manter 0 registro e assegurar a propriedade intelectual e os direitos de uso dos genes registrados, e pelo sojicultor, que é responsável pelos campos de produção de sementes. Para melhor entendimento das relações entre esses segmentos, a indústria de produção de sementes de soja pode ser observada na Figura 1.

Figura 1 - Segmentos da Industria de Produção de Sementes de Soja

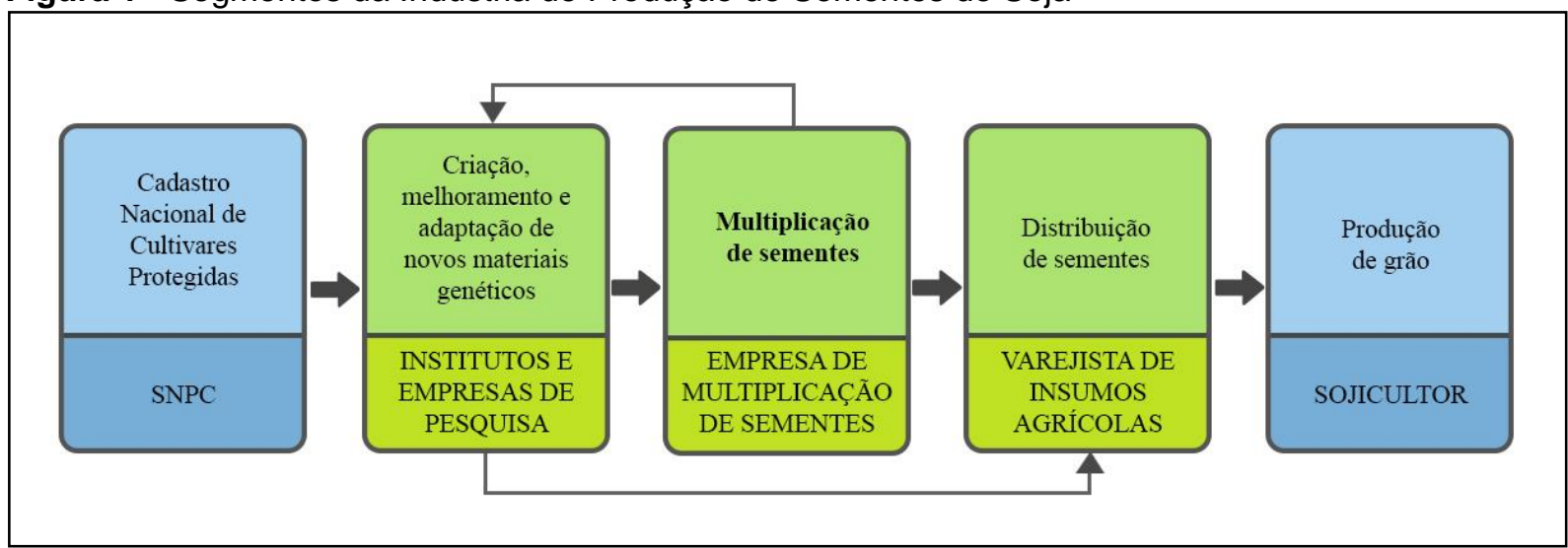

Fonte: Lima e Bueno (2001)

O presente artigo enfoca o segmento da indústria de multiplicação de sementes de soja, que possuem a atribuição de multiplicar a genética desenvolvida por institutos e empresas de pesquisa, sendo elas públicas ou privadas, distribuindo a sua produção direta ou indiretamente aos produtores de soja.

A indústria como a conhecemos, sofreu diversas alterações no decorrer da história, adaptando-se ao longo das descobertas e evoluções tecnológicas. O conjunto de desdobramentos nos âmbitos sociais, políticos e econômicos desencadeados por essas evoluções segregam o que denominamos "revoluções industriais", sendo que atualmente vivenciamos o início da quarta revolução (DOMBROWSKI; WAGNER, 2014). Marcada pela digitalização da operação industrial, sendo denominada "Indústria 4.0", termo originado de um projeto que teve como principal objetivo a modernização da indústria alemã, e contou com a iniciativa de empresas, universidades e do Governo alemão. $O$ termo foi citado pela primeira vez durante a Hannover Fair 2011, principal feira mundial voltada para tecnologia industrial (KAGERMANN, 2013). 
Haja vista que existem várias definições para a Indústria 4.0, bem como as inovações tecnológicas que a caracterizam, segundo Hermann, Pentek e Otto (2016) a Indústria 4.0 integra quatro componentes chave que possibilitam a criação de uma plataforma colaborativa de manufatura, sendo eles: a internet das coisas (IoT Internet of Things), internet dos serviços (loS - Internet of Services), sistemas cyberfísicos (CPS - Cyber Physical System) e as fábricas inteligentes (Smart Factory). Os autores salientam ainda que a comunicação M2M (Machine to Machine) e componentes inteligentes não são considerados componentes independentes da Indústria 4.0, visto que a comunicação M2M nada mais é que um facilitador da loT, e produtos inteligentes devem ser considerados subcomponentes do CPS. Complementam ainda que Cloud e Big-Data consistem em serviços de dados que utilizam informações geradas por meio da implementação da Indústria 4.0, não sendo considerados componentes independentes.

Muitas indústrias brasileiras já automatizaram seus processos, mas esse é apenas o primeiro passo. A indústria 4.0 é composta por duas vertentes: processos integrados e produtos inovadores, o Brasil ainda precisa caminhar muito nos dois sentidos, possuindo poucos setores competitivos em escala global (ESTÚDIO ABC, 2016).

$\mathrm{Na}$ indústria 4.0, boa parte dos sistemas de controles, sensores e equipamentos estão conectados a redes, transportadores, seres humanos entre outros, o que exige uma logística que possibilite uma integração: tecnológica, rápida, conectada e inteligente.

De acordo com Ballou (1993), logística consiste na agregação de valor para os clientes e fornecedores, por meio da integração do fluxo de materiais e informações, que contemplam desde o planejamento e concepção do produto, gerenciamento de fornecedores e matéria prima, armazenagem, distribuição, produção até o transporte.

Esse conceito pode ser entrelaçado com o desenvolvimento de aplicativos voltados para loT, interligando as redes de manufatura, clientes e fornecedores, proporcionando uma integração total. Essa interligação de processos e a junção do movimento que acontece fisicamente com os produtos e serviços ao seu registro digital, ultrapassando as limitações de sistemas e em tempo real, caracterizando o que podemos denominar de logística 4.0 (JUNGHEINRICH, 2017). 
Logística 4.0 é um termo criado a fim de relacionar o uso da indústria 4.0 na área de logística, baseando-se principalmente na utilização de sistemas cyber-físicos em associação com a tecnologia de RFID (Identificação por rádio frequência) (HERMANN; PENTEK; OTTO, 2016).

O RFID é uma sigla utilizada para Radio Frequency Identification, ou em português, Identificação por Rádio Frequência. Trata-se de uma tecnologia recente, com surgimento na década de 1980, sua principal função é a identificação por ondas de rádio, com alcances variáveis, de acordo com o chip utilizado. Toda comunicação é feita por meio de uma etiqueta que contém um chip RFID, que envia sinais até um leitor específico, transferindo via Software todos os dados e informações significativas (DUROC; KADDOUR, 2012).

Chinelato (2010) discorre que as etiquetas ou tags são os principais componentes da tecnologia RFID, podendo executar funções de apenas leitura ou leitura e gravação. As etiquetas ou tags que possuem apenas a função de leitura, são pré-programadas com uma identificação única, já as que dispõem da função de leitura e gravação são utilizadas para aplicações que requerem a atualização de dados de forma dinâmica.

Como qualquer outra tecnologia, a RFID possui vantagens e desvantagens. Prediger, Silveira e Freitas (2016) descrevem algumas vantagens, sendo elas: não necessitar de contato visual nem físico entre a etiqueta ou tag e o leitor; leitura rápida, simultânea e automática; contagens instantâneas para sistemas empresarias de inventário; maior capacidade de armazenamento de dados, informações que podem ser escritas/reescritas e apagadas; precisão nas informações; resistência a algumas condições naturais como poeira, umidade e temperatura. Já com relação as desvantagens, os autores ressaltam: custo elevado comparada a outras soluções de identificação; aumento do custo final dos produtos, não apenas por conta das etiquetas ou tags, mas também por conta da infraestrutura necessária para o funcionamento da tecnologia; necessidade de padronização das frequências utilizadas para que os produtos possam ser lifos por toda a indústria; além de que determinados ambientes com materiais metálicos e condutivos podem afetar 0 funcionamento/alcance do sistema.

A tecnologia RFID possui grande potencial de aplicabilidade prática em diversos segmentos, sendo que a área da logística é uma delas. 
A utilização do RFID na cadeia logística possui diferentes objetivos e funcionalidades, mas sempre com o intuito de proporcionar suporte aos sistemas de informação. Conforme Nassar e Vieira (2014) algumas aplicações do RFID na logística incluem:

- Controle de estocagem;

- Identificação de cargas e contêineres;

- Monitoramento e rastreabilidade no transporte; e

- Transferência de dados entre os participantes do processo logístico.

Ainda de acordo com Nassar e Vieira (2014), o RFID pode ser aplicado em diversos momentos no processo logístico. Adotando as tags ou etiquetas com a finalidade de controle de armazenagem e monitoramento da movimentação dos produtos, saindo da produção até o desembarque nas prateleiras do consumidor final.

\section{MÉTODO}

Para responder as questões propostas nesse trabalho, é utilizado o método do estudo de caso, visto que o mesmo se enquadra nos objetivos propostos e privilegia o contato direto com o fato ou fenômeno observado. Esse método é caracterizado pelo estudo de fenômenos contemporâneos, no contexto real e livre de manipulação, buscando responder questões de investigação do tipo "como" e "porquê" (YIN, 2005).

Quanto aos fins, a pesquisa é descritiva-exploratória, haja vista que busca descobrir ideias e soluções, na tentativa de adquirir maior familiaridade com o objeto de estudo, apresenta fato ou fenômeno e levanta observações sistemáticas no decorrer da pesquisa. Descritiva, por definir a natureza e apresentar as características de um fenômeno em um grupo específico (SELLTIZ; WRIGHTSMAN, 1987), que no presente estudo é a implementação da tecnologia RFID em uma indústria de produção de sementes.

A pesquisa realizada é exploratória, no sentido de que existe pouco conhecimento acumulado e sistematizado sobre o tema RFID, sua aplicabilidade na indústria de sementes de soja e pela profundidade da pesquisa. A abordagem da pesquisa é qualitativa, em função dos métodos de coleta de dados utilizados, haja vista que o pesquisador se envolveu diretamente com o problema e com a coleta de informações (DIEHL; TATIM, 2004). 
Quanto à coleta de dados, foram utilizados: pesquisa bibliográfica, para a elaboração do referencial teórico; documentos internos da organização e de fornecedores de tecnologia RFID e observação em visitas técnicas a empresa; PoC Prova de conceito.

PoC - Proof of Concept, ou prova de conceito em português, consiste em um modelo prático que possa provar um conceito teórico, estabelecido por um artigo técnico. Na área de tecnologia da informação, o termo está relacionado ao desenvolvimento de um protótipo como ferramenta para provar a viabilidade de um determinado projeto. A PoC é a evidência documentada de que um determinado produto ou serviço potencial pode ser bem-sucedido, auxiliando o pesquisador na identificação de problemas técnicos e logísticos potenciais que possam interferir nos resultados esperados (GAEA, 2017).

A PoC realizada nesse artigo, tomou como base a proposta metodológica feita por (PASTANA, 2012), com a finalidade de aumentar o nível de assertividade na seleção das melhores tecnologias a serem aplicadas em campo. A metodologia consiste em 3 fases, sendo elas: caracterização do problema, determinação de requisitos e elaboração do projeto prático.

$\mathrm{Na}$ fase 1 foram levantadas as principais dificuldades enfrentadas na logística interna, no qual a tecnologia de RFID se propõe a solucionar. A logística interna em questão tem como abrangência de atuação os processos de embalagem, endereçamento, posicionamento físico no armazém, movimentação interna e expedição do produto acabado.

$\mathrm{Na}$ fase 2 foram apontados os requisitos da solução proposta, não apenas no ponto de vista das regras de negócio, mas também no contexto técnico.

A fase 3 contemplou a transferência de soluções de negócio para soluções puramente tecnológicas, ao final dessas três fases, obteve-se de maneira clara:

- Todos os pontos de controle onde teremos a adoção da tecnologia de RFID;

- Principais recursos tecnológicos a serem utilizados; e

- Necessidade de adequação física do ambiente a ser realizado o PoC.

Com a estrutura pronta, foram testadas as tags de RFID a fim de selecionar a mais adequada para o tipo de embalagem utilizada na indústria de sementes. Sendo necessário um nível de assertividade de leitura da tecnologia de 100\%, para averiguar essa premissa, foi executado o processo de leitura de cada modelo de etiqueta 
selecionada 100 vezes, descartando a etiqueta que não atingiu $100 \%$ de assertividade.

Para avaliar a viabilidade econômica, foram utilizados os principais indicadores tangíveis na avaliação de projetos de tecnologia da informação, como VPL - Valor Presente Líquido e Payback Descontado, levando em consideração também que tais indicadores são utilizados atualmente pela empresa onde realizou-se a pesquisa para avaliar a viabilidade econômica de projetos.

Os resultados deste artigo não tiveram a pretensão de ser representativos do universo, considerando que a pesquisa é classificada como qualitativa exploratória, haja vista que a intenção foi avaliar a viabilidade econômica de implementação da tecnologia de RFID na logística interna da indústria de produção de sementes de soja.

\section{RESULTADOS E DISCUSSÃO}

Conforme previsto na metodologia proposta por Pastana (2012), a PoC realizada foi segmentada em 3 fases, sendo elas: Fase 1 - Caracterização do problema; Fase 2 - Determinação dos requisitos; Fase 3 - Projeto tecnológico prático.

A fim de alcançar tais objetivos, foram realizadas reuniões com a equipe de gestão e operação, consultas a documentos internos e visitas técnicas ao parque industrial da empresa. Foram analisadas todas as fases dos processos de embalagem, endereçamento, posicionamento físico no armazém, movimentação interna e expedição do produto conforme detalhamento.

Seguindo o método proposto, uma vez entendido o escopo geral dos processos intrínsecos na logística interna da indústria de semente de soja, foi possível estabelecer um macroprocesso com sequenciamento lógico entre as etapas. A fim de facilitar o entendimento, foi elaborado o desenho do macroprocesso em formato de $\mathrm{BPMN}^{2}$ - Business Process Modeling Notation.

A Figura 2 representa o macroprocesso analisado.

\footnotetext{
${ }^{2}$ BPMN - Business Process Modeling Notation, em português, Modelo e Notação de Processos de negócios, foi criado para projetar e modelar processos de negócio e suas transformações na linguagem de execução.
} 
Figura 2 - Macroprocesso da logística interna

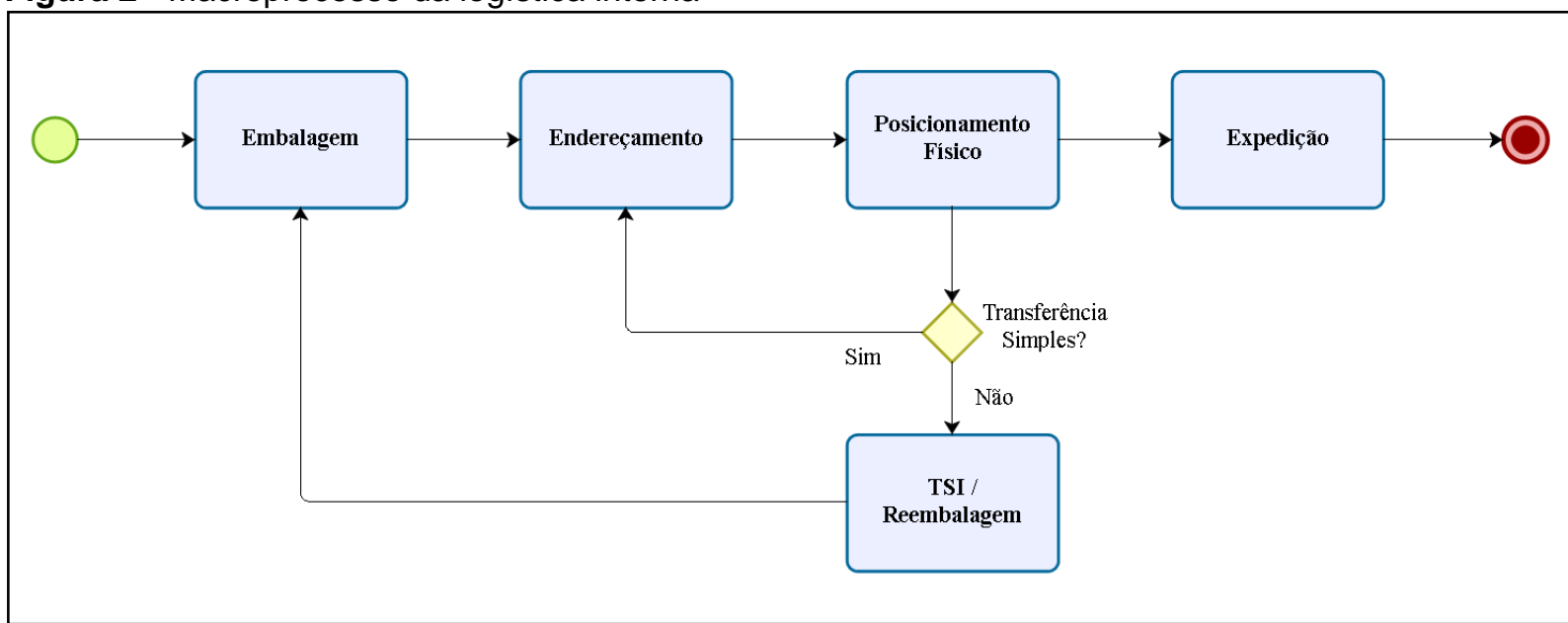

Fonte: Elaboração própria

A partir do acompanhamento de todo o processo, foi possível levantar as principais dificuldades enfrentadas na logística interna conforme apresentado no Quadro 1.

Quadro 1 - Dificuldades levantadas e soluções propostas (continuação)

\begin{tabular}{|c|c|}
\hline \multicolumn{2}{|c|}{ PROCESSO DE EMBALAGEM } \\
\hline Dificuldade Levantada & Solução Proposta \\
\hline $\begin{array}{l}\text { Ao danificar uma etiqueta, a mesma deve ser } \\
\text { reimpressa com o mesmo QR Code. O operador } \\
\text { precisa realizar um lançamento sistêmico para } \\
\text { reimprimir a etiqueta com o QR Code novo e } \\
\text { realizar a baixa da etiqueta anterior. }\end{array}$ & $\begin{array}{l}\text { Com o RFID não seria necessária a reimpressão } \\
\text { da etiqueta. No ato da impressão inicial das } \\
\text { etiquetas do lote produzido, o operador poderia } \\
\text { imprimir etiquetas sobressalentes, quando o } \\
\text { operador for realizar o apontamento da produção } \\
\text { para endereçamento, serão considerados apenas } \\
\text { as etiquetas ou tags RFID que foram utilizadas e } \\
\text { identificadas pela antena. }\end{array}$ \\
\hline \multicolumn{2}{|c|}{ PROCESSO DE ENDEREÇAMENTO } \\
\hline Dificuldade Levantada & Solução Proposta \\
\hline $\begin{array}{l}\text { As informações do local físico onde o produto } \\
\text { deverá ser endereçado são repassadas para o } \\
\text { operador de empilhadeira por meio de um } \\
\text { formulário, o que tem acarretado falhas de } \\
\text { apontamento. }\end{array}$ & $\begin{array}{l}\text { Instalar uma antena e um leitor RFID na } \\
\text { empilhadeira para que as informações do lote a } \\
\text { ser movimentado sejam apresentadas em um } \\
\text { tablet que também será acoplado na } \\
\text { empilhadeira. }\end{array}$ \\
\hline \multicolumn{2}{|c|}{ PROCESSO DE MOVIMENTAÇÃO INTERNA } \\
\hline Dificuldade Levantada & Solução Proposta \\
\hline $\begin{array}{l}\text { Para realizar a movimentação interna de } \\
\text { endereço no mesmo armazém, é necessário o } \\
\text { preenchimento do formulário de movimentação e } \\
\text { posteriormente essa informação é lançada no } \\
\text { sistema de gestão. }\end{array}$ & $\begin{array}{l}\text { Instalar uma antena e um leitor RFID na } \\
\text { empilhadeira para que as informações do lote a } \\
\text { ser movimentado sejam apresentadas em um } \\
\text { tablet que também será acoplado na } \\
\text { empilhadeira. Sendo apresentadas as } \\
\text { informações do local atual e do local de destino } \\
\text { do material a ser movimentado. }\end{array}$ \\
\hline
\end{tabular}


Quadro 2 - Dificuldades levantadas e soluções propostas (conclusão)

\section{PROCESSO DE MOVIMENTAÇÃO INTERNA}

Para realizar a movimentação do produto para o tratamento industrial ou para reembalagem, é necessário o preenchimento do formulário de movimentação e posteriormente essa informação é lançada no sistema de gestão.

\section{Dificuldade Levantada}

\section{PROCESSO DE EXPEDICÃO}

Conferência via leitura de QR Code de todos os materiais a serem expedidos. No caso de produtos que são embalados em sacarias, a conferência tem que ser feita individualmente, o que acarreta uma demora no processo de expedição.

Fonte: Elaboração própria
Instalação de um portal com antenas RFID para

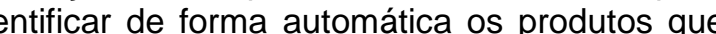
são movimentados para fora do armazém de origem.

A partir das informações levantadas, foi discutido com a equipe de gestão e operação da empresa, quais desses itens trataríamos como objetivos para a elaboração do escopo do projeto inicial. Tendo como resultado os seguintes objetivos demonstrados no Quadro 2.

Quadro 3 - Escopo do projeto
\begin{tabular}{|c|l|}
\hline ITEM & \multicolumn{1}{c|}{ OBJETIVO } \\
\hline 01 & $\begin{array}{l}\text { Promover a otimização do tempo dos colaboradores envolvidos diretamente na logística } \\
\text { interna; }\end{array}$ \\
\hline 02 & $\begin{array}{l}\text { Reduzir a utilização de formulários com preenchimento manual minimizando as falhas de } \\
\text { apontamento e endereçamento; }\end{array}$ \\
\hline 03 & Otimizar o tempo de execução do processo de movimentação interna; \\
\hline 04 & Otimizar o tempo de execução no processo de expedição; \\
\hline 05 & $\begin{array}{l}\text { Identificar uma possível redução no quadro de pessoal envolvido diretamente nos } \\
\text { processos analisados. }\end{array}$ \\
\hline
\end{tabular}

Fonte: Elaboração própria

A fim de delimitar um modelo prático de aplicação do RFID em campo e com base nos objetivos propostos, foi possível estabelecer requisitos possíveis de serem atingidos, fazendo com que a $\mathrm{PoC}$ realizada represente situações reais do processo, podendo assim de fato ser considerada como uma solução.

Para a realização do projeto, foi contratado um fornecedor de tecnologia RFID que atendesse aos requisitos de negócio estabelecidos pela empresa e que possui profissionais qualificados para acompanhar a realização da PoC.

A partir de uma reunião presencial com o fornecedor, foi possível estabelecer os pontos de controle passíveis de aderência a tecnologia RFID, os recursos 
tecnológicos a serem utilizados, assim como as adequações físicas do ambiente necessárias para a realização da PoC, conforme pode ser observado no Quadro 3.

Quadro 4- Pontos de controle, recursos tecnológicos e adequações físicas do ambiente

\begin{tabular}{|c|c|}
\hline ITEM AVALIADO & CONSIDERAÇÕES \\
\hline $\begin{array}{l}\text { Pontos de controle passíveis de aderência da } \\
\text { tecnologia RFID. }\end{array}$ & $\begin{array}{l}\text { Analisando a complexo industrial da unidade de } \\
\text { beneficiamento de sementes, foram identificados } \\
\text { os seguintes pontos de controle passíveis de } \\
\text { instalação de portais RFID ou de coletores } \\
\text { móveis: } \\
\text { - } 2 \text { Portais no processo de embalagem; } \\
\text { - } 1 \text { Portal no tratamento industrial; } \\
\text { - } 1 \text { Coletor móvel no armazém; } \\
\text { - } 1 \text { Coletor móvel na empilhadeira; } \\
\text { - } 2 \text { Portais no processo de expedição. }\end{array}$ \\
\hline $\begin{array}{l}\text { Recursos tecnológicos a serem utilizados na } \\
\text { PoC. }\end{array}$ & $\begin{array}{l}\text { - } 4 \text { antenas RFID para simular } 1 \text { portal; } \\
\text { - } 1 \text { Coletor móvel; } \\
\text { - } 4 \text { modelos de etiquetas passivas, sendo } 2 \\
\text { modelos para bag e } 2 \text { modelos para sacarias, } \\
\text { para cada modelo o fornecedor disponibilizou } \\
\text { uma quantidade de } 100 \text { etiquetas. }\end{array}$ \\
\hline Adequação do ambiente físico. & $\begin{array}{l}\text { Não houve necessidade de adequação física do } \\
\text { ambiente, visto que o fornecedor já possui uma } \\
\text { estrutura metálica móvel e adaptável a diversos } \\
\text { tamanhos de portões. }\end{array}$ \\
\hline
\end{tabular}

Fonte: Elaboração própria

Com as informações levantadas, foi possível prosseguir com a instalação dos equipamentos e realizar os testes de leitura.

Conforme mencionado no Quadro 3, o fornecedor disponibilizou 4 modelos de etiquetas RFID para que fosse possível realizar os testes, sendo 2 modelos destinados a sacaria e 2 modelos destinados ao bag. No entanto apenas uma das etiquetas disponibilizadas para sacaria teve boa fixação, devido a esse motivo, o teste de leitura foi realizado apenas com 3 modelos de etiquetas.

Conforme proposto na metodologia, o teste de aderência da etiqueta consiste em realizar a leitura da mesma 100 vezes, devendo obter $100 \%$ de assertividade em todas as tentativas. No projeto proposto havia dois tipos de leitores, um coletor fixo no Portão 6 da doca de carregamento e um coletor móvel, sendo que foi realizado o teste com ambos os tipos de coletor.

Os resultados dos testes de leitura são apresentados na Tabela 1. 
Tabela 1 - Testes de leitura

\begin{tabular}{lccc}
\multicolumn{1}{c}{ Eescrição } & Modelo & NíVEL DE ASSERTIVIDADE \\
\multicolumn{1}{c}{ Coletor Fixo } & Coletor Móvel \\
\hline Etiqueta de sacaria & 692185 & $100 \%$ & $92 \%$ \\
Etiqueta de bag 1 & 632185 & $100 \%$ & $100 \%$ \\
Etiqueta de bag 2 & 632180 & $100 \%$ & $100 \%$ \\
\hline
\end{tabular}

Fonte: Elaboração própria

Como pode ser observado na Tabela 1, a etiqueta de sacaria obteve $92 \%$ de assertividade de leitura no teste com o coletor móvel. Tal resultado influencia diretamente na contagem de inventário que o projeto propõe a ser realizado com o coletor móvel, no entanto a mesma não é desqualificada para a utilização em todos os pontos de controle que são utilizados os coletores fixos. Já as etiquetas de bag obtiveram $100 \%$ de assertividade independentemente do coletor utilizado.

Durante a realização da PoC puderam ser observados 4 principais aspectos que podem afetar a adoção da tecnologia RFID na indústria de sementes, sendo eles:

- Alta movimentação de produtos acabados - muitas vezes sendo necessário movimentar o produto para outro armazém, para realização de troca de embalagem ou para realização do tratamento industrial. Essa movimentação cria a necessidade da instalação de mais portais RFID para que a movimentação do produto entre ambientes seja registrada de forma automática.

- A paletização da semente na embalagem de sacaria de 40 quilos - fazendo com que seja necessário um alto nível de concentração do operador ao realizar a empilhamento da mesma no palete. Já que é necessário manter todas as etiquetas RFID com a face voltada para fora, a fim de facilitar a leitura da mesma. Essa necessidade se deve, de acordo com o técnico da empresa fornecedora da tecnologia, a densidade e a umidade da semente que podem influenciar de maneira negativa na propagação do sinal RFID.

- A disposição e acomodação dos produtos no armazém - que dificultam a contagem do estoque com a tecnologia RFID, pois os blocos são muito próximos um dos outros com a finalidade de otimizar o espaço de ocupação. Portanto, tal disposição dos produtos dificulta a leitura das etiquetas que podem ficar escondidas entre os blocos. Além disso, por meio dos testes realizados, observou-se que o coletor manual capturava não somente os 
tags do bloco que estava sendo conferido, mas também do bloco posicionado na lateral, o que dificulta a conferência.

- A necessidade de adequações sistêmicas - para interligar a tecnologia RFID ao sistema de gestão da empresa. Pois existe a necessidade de realizar toda uma parametrização caso o sistema já esteja adaptado para a tecnologia, caso não esteja é necessário o desenvolvimento de interfaces de comunicação o que pode resultar em uma alta complexidade de implementação da tecnologia.

Vale ressaltar que a unidade de beneficiamento de sementes onde foi realizada a PoC é a que possuía maior nível tecnológico na empresa pesquisada, nesse contexto, caso a PoC fosse realizada em outra unidade de beneficiamento de sementes o resultado poderia ter sido diferente.

Para avaliar a viabilidade econômica, conforme definido na metodologia, foram calculados os indicadores de VPL - Valor Presente Líquido e Payback Descontado. Para tanto foi necessário estabelecer os parâmetros para a elaboração do fluxo de caixa, identificando o valor do investimento no projeto, assim como o retorno que o mesmo pode oferecer.

Para compor o valor do investimento do projeto, foi levantado o custo de aquisição de todos os recursos necessários para que a tecnologia RFID possa ser implementada conforme pontos de controle definidos no item 4.2.3, levando em consideração a unidade de beneficiamento de sementes onde foi realizada a PoC. Ressalta-se que o custo da etiqueta foi considerado apenas como investimento no primeiro ano, já que a partir do segundo a etiqueta foi considerada como custo da operação, absorvido pela margem de lucro da semente vendida.

Para a definição da quantidade de etiquetas, foi levada em consideração uma produção anual de 700.000 sacas de sementes, totalizando um volume estimando de 28.000.000 de quilos de semente, sendo que 80 \% dessa produção será embalada em bags de 1.000 quilos e $20 \%$ em sacaria de 40 quilos, conforme informado pela equipe de gestão da empresa pesquisada.

O valor do investimento do projeto pode ser observado no Quadro 5. 
Quadro 5 - Investimento do Projeto

\begin{tabular}{|l|c|l|l|}
\hline \multicolumn{1}{|c|}{ RECURSO } & QUANTIDADE & \multicolumn{1}{c|}{ VALOR UNITÁRIO } & \multicolumn{1}{c|}{ VALOR TOTAL } \\
\hline $\begin{array}{l}\text { Etiqueta RFID } \\
\text { Sacaria }\end{array}$ & 140.000 & $\mathrm{R} \$ 0,15$ & $\mathrm{R} \$ 21.000,00$ \\
\hline Etiqueta RFID - Bag & 22.400 & $\mathrm{R} \$ 0,48$ & $\mathrm{R} \$ 10.752,00$ \\
\hline Coletor RFID Fixo & 5 & $\mathrm{R} \$ 9.600,00$ & $\mathrm{R} \$ 48.000,00$ \\
\hline Antena RFID & 20 & $\mathrm{R} \$ 550,00$ & $\mathrm{R} \$ 11.000,00$ \\
\hline Coletor RFID Móvel & 2 & $\mathrm{R} \$ 4.900,00$ & $\mathrm{R} \$ 9.800,00$ \\
\hline Licença de Software & 1 & $\mathrm{R} \$ 12.500,00$ & $\mathrm{R} \$ 12.500,00$ \\
\hline Mão de obra instalação & 1 & $\mathrm{R} \$ 8.500,00$ & $\mathrm{R} \$ 8.500,00$ \\
\hline \multicolumn{2}{|l}{ INVESTIMENTO TOTAL } & $\mathbf{R} \$ \mathbf{1 2 1 . 5 5 2 , 0 0}$ \\
\hline
\end{tabular}

Fonte: Elaboração própria

Para estabelecer o retorno do projeto, foi considerada a redução de um dos conferentes do armazém, já que a tecnologia RFID possibilitou que o operador de empilhadeira absorvesse a atividade quase que em sua totalidade de um dos conferentes. Tal atividade consistia em preencher os formulários e realizar o lançamento das movimentações no sistema, atividades que com o coletor instalado na empilhadeira, pode ser executado pelo próprio operador de empilhadeira. Segundo informações da gestão da empresa, o conferente possui um custo mensal aproximado de $R \$ 4.180,00$ considerando salário, encargos e benefícios, o que nos leva a um retorno anual de $\mathrm{R} \$ 50.160,00$.

Para análise de projetos, a empresa utiliza uma TMA - Taxa Mínima de Atratividade, ou taxa de desconto de $10 \%$ ao e uma expectativa de retorno sobre o investimento de projetos de tecnologia da informação de no máximo 4 anos.

Tendo em vista os dados coletados e o fluxo de caixa estabelecido foi possível calcular os indicadores de VPL - Valor Presente Líquido e Payback Descontado conforme demonstrado na Tabela 2.

A partir da análise dos dados demostrados a partir da Tabela 2, pode ser constatado que o projeto possui um VPL - Valor Presente Líquido de $\mathrm{R} \$ 37.448,45$ ao final de 4 anos, ou seja, a receita ao final do período foi positiva, caracterizando a viabilidade do projeto. Continuando com a análise, pode-se observar que o resultado do Payback Descontado foi de 3 anos e 27 dias, o que significa que ao final desse período, todo o investimento aplicado no projeto foi recuperado, atendendo assim as expectativas de retorno do investimento estipuladas pela empresa de 4 anos, sendo que, dessa forma o projeto demonstrou-se viável. 
Tabela 2 - Fluxo de Caixa e Resultado dos Indicadores

\begin{tabular}{|c|c|c|c|c|c|}
\hline 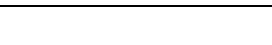 & ANO 00 & ANO 01 & ANO 02 & ANO 03 & ANO 04 \\
\hline $\begin{array}{l}\text { FLUXO DE } \\
\text { CAIXA FINAL }\end{array}$ & $\begin{array}{l}-\mathrm{R} \$ \\
121.552,00\end{array}$ & $\mathrm{R} \$ 50.160,00$ & $\mathrm{R} \$ 50.160,00$ & $R \$ 50.160,00$ & $R \$ 50.160,00$ \\
\hline $\begin{array}{l}\text { FLUXO DE } \\
\text { CAIXA } \\
\text { ACUMULADO }\end{array}$ & $\begin{array}{l}-\mathrm{R} \$ \\
121.552,00\end{array}$ & $-\mathrm{R} \$ 71.392,00$ & $-R \$ 21.232,00$ & $\mathrm{R} \$ 28.928,00$ & $\mathrm{R} \$ 79.088,00$ \\
\hline $\begin{array}{l}\text { FLUXO DE } \\
\text { CAIXA } \\
\text { DESCONTADO }\end{array}$ & $\begin{array}{l}-\mathrm{R} \$ \\
121.552,00\end{array}$ & $\mathrm{R} \$ 45.600,00$ & $\mathrm{R} \$ 41.454,55$ & $\mathrm{R} \$ 37.685,95$ & $\mathrm{R} \$ 34.259,95$ \\
\hline $\begin{array}{l}\text { FLUXO DE } \\
\text { CAIXA } \\
\text { DESCONTADO } \\
\text { ACUMULADO } \\
\text { TMA }\end{array}$ & $\begin{array}{l}-R \$ \\
121.552,00 \\
10 \%\end{array}$ & $-\mathrm{R} \$ 75.952,00$ & $-\mathrm{R} \$ 34.497,45$ & $\mathrm{R} \$ 3.188,50$ & $\mathrm{R} \$ 37.448,45$ \\
\hline VPL & $\mathrm{R} \$ 37.448,45$ & & & & \\
\hline TIR & $23,56 \%$ & & & & \\
\hline $\begin{array}{l}\text { PAYBACK } \\
\text { SIMPLES } \\
\text { PAYBACK } \\
\text { DESCONTADO }\end{array}$ & $\begin{array}{l}\text { Ano: } 03 \\
\text { Ano: } 03\end{array}$ & $\begin{array}{l}\text { Mês: } 05 \\
\text { Mês: } 00\end{array}$ & $\begin{array}{l}\text { Dia: } 24 \\
\text { Dia: } 27\end{array}$ & & \\
\hline
\end{tabular}

A partir dos resultados obtidos através dois indicadores propostos, pode-se afirmar que o projeto é viável pelo ponto de vista econômico.

\section{CONSIDERAÇÕES FINAIS}

Esta pesquisa teve como objetivo principal avaliar a viabilidade econômica de implementação de RFID na indústria de sementes de soja. O estudo de caso realizado contemplou a execução de uma PoC - Prova de Conceito, que possibilitou os autores colocarem em prática um conceito teórico, evidenciando que um determinado produto ou serviço potencial pode ser bem-sucedido.

Durante a realização da PoC foram determinados objetivos a serem atendidos pelo projeto prático. Abaixo seguem os resultados obtidos e as considerações acerca de cada um:

- Objetivo 1: Promover a otimização do tempo dos colaboradores envolvidos diretamente na logística interna. Pode ser observado que as tarefas simuladas a partir da implementação do RFID melhoraram se forma 
significativa, reduzindo o tempo de execução por eliminar partes do processo, como é o exemplo do preenchimento de fichas de forma manual. Sendo assim o objetivo foi atingido;

- Objetivo 2: Reduzir a utilização de formulários com preenchimento manual. Observou-se que com a tecnologia RFID é possível eliminar por completo os formulários de preenchimento manual, dessa forma o objetivo foi atingido;

- Objetivo 3: Otimizar o tempo de execução do processo de movimentação interna. Com a instalação do coletor móvel na empilhadeira, foi possível automatizar o processo de movimentação interna, eliminando a ação do conferente de realizar o lançamento de tais movimentações no sistema de gestão da empresa, pois, todas as informações de transferência ficam disponíveis no coletor de dados onde o próprio operador de empilhadeira consegue realizar todos os lançamentos necessários, concluindo assim que o objetivo foi atingido;

- Objetivo 4: Otimizar o tempo de execução do processo de expedição. O tempo de execução do processo de expedição foi otimizado, já que com o RFID é necessário apenas a confirmação da ordem de carregamento pelo operador, já que todos os produtos são identificados pelo portal no momento em que são movimentados para a doca de expedição. Dessa forma constata-se que o objetivo foi atingido;

- Objetivo 5: Identificar uma possível redução no quadro de pessoal - Foi constatado que a partir da implementação do RFID seria possível a redução de 1 conferente no armazém, já que sua principal atividade consistia em realizar o preenchimento dos formulários de forma manual e também realizar tais lançamentos no sistema de gestão, portanto o objetivo foi atingido;

Dessa forma pode ser observado que 5 dos 5 objetivos estabelecidos foram atingidos, demostrando assim, que a implementação da tecnologia se demonstrou viável, em atendimento aos requisitos técnicos e de negócio previamente estabelecidos.

Com relação ao aspecto financeiro, a partir da análise dos indicadores estabelecidos pelos autores, o projeto demonstrou ser viável. 
Conclui-se então a partir dos dados analisados, que a implementação da tecnologia RFID se demonstrou viável sob o ponto de vista econômico.

Podemos ressaltar como limitação da pesquisa, a escassez de outros trabalhos acadêmicos que abordam o tema específico para efeitos comparativos. Assim como a limitação da PoC que conseguiu simular a maioria dos processos executados na logística interna, mas de forma parcial devido a limitação no quantitativo de equipamentos que foram disponibilizados.

Outro fator limitante foi que o estudo de caso único não tem representatividade expressiva da indústria de produção de sementes de modo geral.

Como proposição para estudos futuros, sugere-se a realização de estudos da aplicabilidade do RFID em outros processos industriais, assim como em outros ramos de negócio relacionados a agricultura. Isso possibilitaria identificar novas oportunidades de implementação, facilitando a difusão da tecnologia no agronegócio e reduzindo seus custos de implementação de maneira gradativa.

\section{REFERÊNCIAS}

BALLOU, Ronald H. Logística empresarial: transportes, administração de materiais e distribuição física. 1. ed. [S.I.]: Atlas, 1993. Disponível em: https://books.google.com.br/books?id=p6CIPgAACAAJ.

CEPEA, Centro de Estudos Avançados em Economia Aplicada. PIB do Agronegócio Brasileiro - Centro de Estudos Avançados em Economia Aplicada - CEPEA-Esalq/USP. 2017. Disponível em: https://www.cepea.esalq.usp.br/br/pib-do-agronegocio-brasileiro.aspx. Acesso em: 16 nov. 2017.

CHINELATO, Charles. Tecnologia de Identificação por Radiofreqüência - RFID Aplicada em Sistemas de Gerenciamento de Armazéns (WMS - Warehouse Management System). p. 111, 2010. Disponível em: https://repositorio.ucs.br/xmlui/bitstream/handle/11338/1442/TCC Charles Chinelato. pdf? sequence $=3 \&$ isAllowed $=y \#$ page $=1$ \&zoom=auto,-265,539. Acesso em: 7 nov. 2017.

CHRISTENSEN, Clayton; MCDONAD, Rory; ALTMAN, Elizabeth J.; PALMER, Jonathan. Disruptive Innovation: Intellectual History and Future Paths. Academy of Management Proceedings, v. 2017, n. 1, p. 14218, 2017. Disponível em: https://www.uniba.it/docenti/sommaernesto/17057_2059672ce9fb4df99f3e2654b9b1c2a9.pdf. Acesso em: 3 out. 2018.

CNA, Confederação da Agricultura e Pecuária; CEPEA, Centro de Estudos Avançados em Economia Aplicada. Botetim PIB. 2017. Disponível em: http://www.cnabrasil.org.br/boletins/boletim-pib-agropecuaria-segue-em-alta-amenizandoretracao-do-agronegocio-outubro-2017\#. 
CONAB, Companhia Nacional de Abastecimento. Acompanhamento da safra brasileira: café. Monitoramento agricola- Safra 2017, v. 4, n. 1, p. 1-98, 2017. Disponível em: http://www.conab.gov.br.

DIEHL, Astor Antônio; TATIM, Denise Carvalho. Pesquisa em Ciências Sociais Aplicadas. 1. ed. São Paulo: [s.n.], 2004.

DOMBROWSKI, Uwe; WAGNER, Tobias. Mental strain as field of action in the 4th industrial revolution. Procedia CIRP, v. 17, p. 100-105, 2014. Disponível em: www.sciencedirect.com. Acesso em: 2 dez. 2017. https://doi.org/10.1016/j.procir.2014.01.077

DUROC, Yvan; KADDOUR, Darine. RFID potential impacts and future evolution for green projects. Energy Procedia, v. 18, p. 91-98, 2012. Disponível em:

http://dx.doi.org/10.1016/j.egypro.2012.05.021

ESTÚDIO ABC. O Brasil está pronto para a indústria 4.0? | EXAME. Disponível em: https://exame.abril.com.br/tecnologia/o-brasil-esta-pronto-para-a-industria-4-0/. Acesso em: 13 fev. 2018.

GAEA, Consulting. Por que é importante fazer uma prova de conceito? (PoC). Disponível em: https://gaea.com.br/por-que-e-importante-fazer-uma-prova-de-conceito/. Acesso em: 21 fev. 2018.

HERMANN, Mario; PENTEK, Tobias; OTTO, Boris. Design principles for industrie 4.0 scenarios. Proceedings of the Annual Hawaii International Conference on System Sciences, v. 2016, p. 3928-3937, March 2016. https://doi.org/10.1109/HICSS.2016.488

HOLANDA, Jonathas. ABRASS - Associação Brasileira dos Produtores de Sementes de Soja. [S.d.]. Disponível em: http://abrass.com.br/semente-de-soja/. Acesso em: 11 fev. 2018.

JUNGHEINRICH. Logística 4.0 e a importância da tecnologia na integração de processos. Disponível em: http://www.tudosobrelogistica.com.br/logistica-4-0-e-aimportancia-da-tecnologia-na-integracao-de-processos/. Acesso em: 13 fev. 2018.

KAGERMANN, Henning. Recommendations for implementing the strategic initiative INDUSTRIE 4.0. Final report of the Industrie 4.0 WG. [S.I: s.n.], 2013.

LIMA, Dário de Oliveira Filho; BUENO, Luiz Carlos. O agronegócio da soja: análise competitiva da indústria de produção de sementes de soja em Mato Grosso do Sul. p. 1-15, 2001.

MICHELS, Ido Luiz et al. Estudo das cadeias produtivas de Mato Grosso do Sul: sojicultura. v. 10, 2003.

MOREIRA, Fabiano Greter; ARRUDA, Josiane Mendes De; SILVA, Aline Juliana Da. A cooperação como fortalecimento da cadeia produtiva de soja: uma análise na coopergrãos no município de nova andradina (ms). Revista Brasileira de Administração Científica, v. 6, n. 1, p. 240-253, 2015. https://doi.org/10.6008/SPC2179-684X.2015.001.0015

NASSAR, Victor; VIEIRA, Milton Luiz Horn. A aplicação de RFID na logística: um estudo de caso do Sistema de Infraestrutura e Monitoramento de Cargas do Estado de Santa Catarina. Gestão \& Produção, v. 21, n. 3, p. 520-531, 2014. Disponível em:

https://www.researchgate.net/profile/Victor_Nassar3/publication/305221778_A_aplicacao_de 
_RFID_na_logistica_um_estudo_de_caso_do_Sistema_de_Infraestrutura_e_Monitoramento _de_Cargas_do_Estado_de_Santa_Catarina/links/578538d508aec5c2e4e11a45/A-

aplicacao-de-R. Acesso em: 6 nov. 2017. https://doi.org/10.1590/0104-530X966

PASTANA, Érico de Souza. Metodologia para aplicação de RFID em automação : estudo de caso em um sistema de gestão. 2012.

PREDIGER, Daniel; SILVEIRA, Sidnei Renato; FREITAS, Edison Pignaton De. Modelo de aplicabilidade de sistema rfid para rastreabilidade na indústria alimentícia. Revista de Sistemas e Computação, v. 6, n. 1, p. 3-14, 2016.

SALATINO, Antônio. Revista Recreio - Grão e Semente: Diferenças. Disponível em: http://recreio.uol.com.br/noticias/culinaria-divertida/grao-e-sementediferencas.phtml\#.WoCC3MIG2iM. Acesso em: 11 fev. 2018.

SELLTIZ, Claire; WRIGHTSMAN, Lawrence S. Métodos de pesquisa nas relações sociais: Delineamentos de pesquisa. 2. ed. [S.I.]: E.P.U, 1987. Disponível em: https://books.google.com.br/books?id=KI7KQwAACAAJ. (Métodos de pesquisa nas relações sociais).

YIN, Robert K. Estudo de Caso: planejamento e métodos. 3. ed. Porto Alegre: [s.n.], 2005.

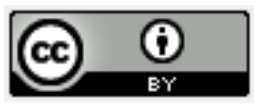

Artigo recebido em: 20/04/2019 e aceito para publicação em: 01/12/2019

DOI: http://dx.doi.org/10.14488/1676-1901.v19i4.3619 